\title{
A INCIDÊNCIA DA QUALIFICADORA DO FEMINICÍDIO EM CRIMES PRATICADOS CONTRA VÍTIMAS TRANSEXUAIS
}

\section{THE INCIDENCE OF THE FEMICIDE QUALIFIER IN CRIMES PRACTICED AGAINST TRANSSEXUAL VICTIMS}

\author{
Clara Gabriela Gouveia Monteiro*
}

\begin{abstract}
RESUMO
Nesta pesquisa investiga-se acerca da possibilidade da incidência da qualificadora do feminicídio em casos de crimes contra vítimas transexuais, partindo do pressuposto que a mulher transexual também está submetida à violência de gênero assim como a mulher cisgênero. Busca-se também compreender a finalidade da lei que criou a referida qualificadora por meio de princípios de interpretação da lei penal, bem como abordar conceitos acerca da diferença entre os termos "sexo" e "gênero" e como sua compreensão é indispensável para este estudo. A metodologia utilizada foi o levantamento bibliográfico aliado ao estudo de jurisprudência, com o objetivo de analisar os diferentes posicionamentos da doutrina e compará-los com a aplicação nos tribunais. A pesquisa qualitativa e os estudos de casos realizados permitem entender a aplicabilidade e a visibilidade da temática nos tribunais brasileiros. Atingidos os objetivos, a pesquisa possibilita constatar a relevância e necessidade de alterações legislativas na qualificadora do feminicídio para que se preserve a segurança jurídica e resguarde os direitos fundamentais de todas as mulheres, alcançando, igualmente, a população transexual.
\end{abstract}

Palavras-chave: Feminicídio. Transexual. Interpretação extensiva. Identidade de gênero.

\begin{abstract}
This research is an analysis of the possibility of the incidence of femicide qualifier cases of crimes against transsexual victims, assuming that the transsexual woman is also subjected to gender violence as well as the cisgender woman. It is also sought to understand the purpose of the law that created the said qualifier through principles of interpretation of criminal law. The methodology used was the bibliographic survey combined with the study of jurisprudence, with the objective of analyzing the different positions of the doctrine and comparing them with the application in the courts. Qualitative research, combined with the case studies done, allow us to understand the applicability and visibility of the theme in Brazilian courts. Once the objectives are achieved, the research makes it possible to verify the relevance and the need of a legislative change in the femicide qualifier to preserve legal security and safeguard the fundamental rights of all women, reaching, equally, the transsexual population.
\end{abstract}

Key-words: Femicide. Transsexual. Extensive interpretation. Gender identity.

Artigo submetido em 25 de dezembro de 2021 e aprovado em 09 de fevereiro de 2022.

\footnotetext{
* Graduada em Direito pela Faculdade Mineira de Direito da Pontifícia Universidade Católica de Minas Gerais.
} Advogada. E-mail: claragabrielamont@gmail.com. 


\section{INTRODUÇÃO}

Analisando o contexto histórico e cultural da sociedade como um todo, a mulher sempre foi colocada em uma posição inferior em relação ao homem, muito em virtude do modelo patriarcal em que a sociedade está inserida. Essa situação é retratada em diversas lutas históricas das mulheres por direitos, entre eles, o direito ao tratamento igualitário. Nesse sentido, movimentos feministas espalhados pelo mundo lutam em prol dos direitos básicos das mulheres para uma vida digna como qualquer outro indivíduo. A exemplo disso, é possível citar o emblemático Movimento Sufragista iniciado no final do século XIX pelo direito das mulheres ao voto.

Todavia, essa luta histórica não se baseia apenas no direito ao voto ou na equidade salarial, que, por sinal, ainda é muito desigual no Brasil. A luta diária das mulheres é também pela própria vida, visando combater a violência de gênero, ou seja, a violência que mulheres sofrem em razão do simples fato de serem mulheres e, consequentemente, estarem em uma situação de vulnerabilidade, que é crescente no Brasil e no mundo.

Um dos casos marcantes da violência de gênero e que tomou notoriedade internacional foi o Caso González, também conhecido por "campo algodoeiro", que ocorreu em 2001 no México, no qual oito mulheres foram assassinadas. As famílias das vítimas levaram o caso à Comissão Interamericana de Direitos Humanos (CIDH), tendo em vista que o poder judiciário mexicano não lidou de forma adequada com as investigações das mortes. A CIDH reconheceu que o caso se tratava de homicídio em razão do gênero, qualificando-o como feminicídio.

No Brasil, o marco inicial expressivo de combate à violência de gênero deu-se pela promulgação da Lei 11.340/2006 (Lei Maria da Penha) e, posteriormente, da Lei 13.104/2015, que modificou o Código Penal, acrescentando a qualificadora do feminicídio ao crime de homicídio (art. 121, §2 $2^{\circ}$, VI, do Código Penal) e incluindo-a no rol de crimes hediondos da Lei 8.072/1990.

Contudo, desde o seu advento, a Lei 13.104/2015 suscita diversos questionamentos a seu respeito, em que pese a real aplicabilidade e alcance da qualificadora do feminicídio. Um desses questionamentos se trata da possibilidade de pessoa transexual figurar como vítima no crime de homicídio qualificado pelo inciso VI (feminicídio).

Esse é um debate necessário e atual, como será demonstrado nesta pesquisa por meio da exposição de diferentes posições doutrinárias e de repercussões nos tribunais, visto que se trata da legitimação de direitos garantidos pela Constituição Federal para que não haja tratamento desigual para com uma minoria da população. Em outros ramos do Direito, transexuais já obtiveram diversos direitos reconhecidos, como por exemplo, no Direito Civil, no qual já é possível requerer a alteração do nome e sexo na certidão de nascimento. Todavia, quando conduzido para a esfera penal, o debate depara-se com princípios divergentes dos da esfera cível: é o caso da analogia, que, em se tratando de analogia in malam partem, isto é, que seja prejudicial ao réu, não é permitida no Direito Penal.

Nesse diapasão, para uma parte da doutrina, a transexual jamais poderá ser considerada mulher, ainda que sua aparência seja tipicamente feminina, isso porque, sua genética é, para todos os fins, masculina. Nesse raciocínio, incluir a transexual no sujeito passivo da qualificadora do feminicídio seria fazer analogia com a lei penal e, por ser uma qualificadora, agravaria a situação do réu.

No entanto, para outra parte da doutrina, a transexual pode ser vítima de feminicídio sem que, para isso, seja utilizada a analogia na lei penal. Para isso, é necessário entender qual a finalidade da referida lei e o bem jurídico que busca tutelar.

Portanto, este trabalho tem como objetivo a análise da possibilidade jurídica de a transexual figurar como vítima de feminicídio, fundamentando-se em pesquisas bibliográficas 
e jurisprudenciais. Serão abordados conceitos de interpretação, fontes do Direito Penal bem como diferentes posicionamentos doutrinários acerca do tema.

A realização desta pesquisa contribui diretamente para a busca de uma justiça igualitária e a defesa de direito das transexuais, tratando-se de um tema de grande relevância social, sobretudo, preservando e respeitando os princípios do Direito Penal.

\section{A QUALIFICADORA DO FEMINICÍDIO}

Inicialmente, é necessário entender do que se trata o feminicídio para o Direito Penal. O termo feminicídio é utilizado para denominar uma qualificadora do crime de homicídio, previsto no Código Penal. Tal qualificadora está prescrita no art. $121, \S 2^{\circ}$, inciso VI e $\S 2^{\circ}$-A, incisos I e II, do referido Código, na seguinte redação:

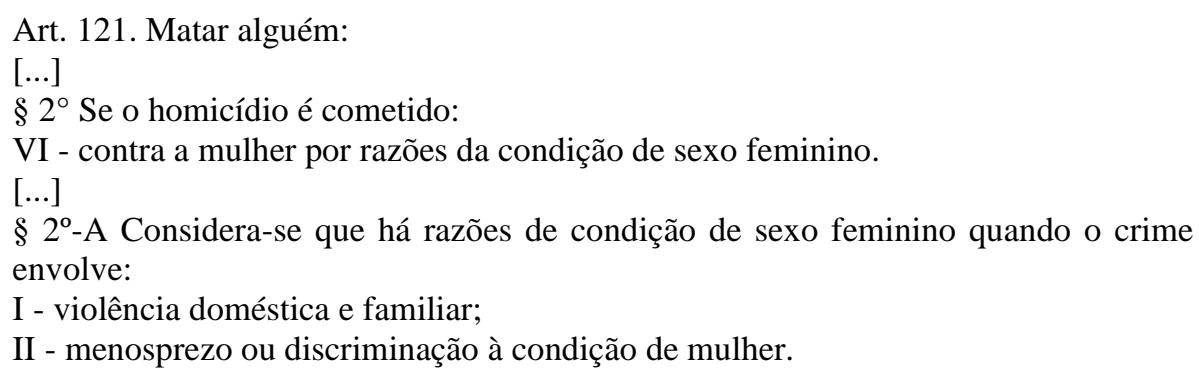

Trata-se de um homicídio praticado contra uma mulher em razão da condição do sexo feminino. $\mathrm{O} \S 2^{\circ}$-A explica que a condição do sexo feminino ocorre quando o crime está envolto no contexto de violência doméstica e familiar ou quando há o menosprezo ou discriminação contra a condição de mulher. Nesse sentido, leciona Capez:

[...] feminicídio é o homicídio doloso praticado contra a mulher por 'razões da condição de sexo feminino', ou seja, desprezando, menosprezando, desconsiderando a dignidade da vítima por ser mulher, como se as pessoas do sexo feminino tivessem menos direitos do que as do sexo masculino. A lei pune mais gravemente aquele que mata mulher por 'razões da condição de sexo feminino' (por razões de gênero). Não basta a vítima ser mulher para que exista o crime de feminicídio, é preciso que a morte aconteça pelo simples fato de a vítima ter a condição de sexo feminino. (CAPEZ, 2019, Eрub).

Na hipótese do $\S 2^{\circ}$-A, inciso I, do art. 121 do CP, há uma relação de confiança entre autor e vítima por estarem inseridos em um contexto de relação familiar ou doméstica. Portanto, como exemplo, o marido que mata a esposa porque acha que ela o está traindo pratica o crime de homicídio qualificado pelo feminicídio.

Já na hipótese do inciso II do parágrafo $2^{\circ}$ do art. 121 do $\mathrm{CP}$, trata-se de uma discriminação ou menosprezo em razão de a vítima ser mulher, desse modo, não é necessário que haja uma relação íntima ou, ainda, que autor e vítima se conheçam. Assim explica Fernando Capez:

Quanto ao menosprezo à condição de mulher, surge a ideia do machismo, que faz com que homens ignorantes se sintam superiores às mulheres e que essa condição ainda lhes daria o direito de matar a mulher como ser inferior. (CAPEZ, 2019, Epub). 
Veja-se que a referida qualificadora determina uma condição especial à vítima, devendo esta pertencer ao sexo feminino em ambos os casos citados. Logo, o homem é excluído do sujeito passivo dessa qualificadora.

Em contraponto, diante dessa afirmativa, advém o questionamento se é possível pessoa transexual figurar como vítima de um feminicídio. Para melhor análise da questão proposta, é necessário utilizar-se da interpretação da lei, ou seja, entender qual a finalidade da lei para que então seja possível verificar se o caso hipotético é aplicável.

Como ponto de partida, é fundamental compreender o significado de pessoa transexual e qual sua relação com sexo e gênero.

\subsection{Transexualidade, sexo e gênero}

Para o Conselho Federal de Medicina (CFM), o transexual ou transgênero é a pessoa que não se identifica com o gênero relativo ao seu sexo de nascimento. Assim determina a Resolução do Conselho Federal de Medicina no 2.265/2019:

\footnotetext{
Art. $1^{\circ}$ Compreende-se por transgênero ou incongruência de gênero a não paridade entre a identidade de gênero e o sexo ao nascimento, incluindo-se neste grupo transexuais, travestis e outras expressões identitárias relacionadas à diversidade de gênero.

$\S 1^{\circ}$ Considera-se identidade de gênero o reconhecimento de cada pessoa sobre seu próprio gênero.

$\S 2^{\circ}$ Consideram-se homens transexuais aqueles nascidos com o sexo feminino que se identificam como homem.

$\S 3^{\circ}$ Consideram-se mulheres transexuais aquelas nascidas com o sexo masculino que se identificam como mulher.
}

Portanto, no conceito biológico, mulheres transexuais são pessoas que nasceram com o sistema reprodutor masculino, porém identificam-se como mulher, assumindo uma identidade social feminina e passando, geralmente, por transformações físicas em seu corpo a fim de atingir uma aparência comumente considerada feminina.

Questiona-se ainda a diferença entre sexo e gênero. De acordo com o Dicionário Online de Português, a palavra gênero é conceituada pela "Diferença entre homens e mulheres que, construída socialmente, pode variar segundo a cultura, determinando o papel social atribuído ao homem e à mulher e às suas identidades sexuais".

Por outro lado, o Dicionário determina que sexo é "Aquilo que marca a diferenciação (órgãos genitais) entre o homem e a mulher, delimitando seus papéis na reprodução".

Com base nessas definições, é possível concluir que sexo se refere à determinação biológica, tratando-se de atribuições relacionadas ao sistema reprodutor, composto de órgãos sexuais masculinos ou femininos.

Já o gênero abrange o conceito sociológico do que é ser homem e mulher. $\mathrm{O}$ gênero transcende os órgãos genitais do indivíduo e atinge a sua expressão na sociedade, aquilo que ele e o outro enxergam na condição de indivíduos.

Sobre a reflexão de gênero, Simone de Beauvoir, em sua obra $O$ Segundo Sexo, afirma que:

Ninguém nasce mulher: torna-se mulher. Nenhum destino biológico, psíquico, econômico define a forma que a fêmea humana assume no seio da sociedade; é o conjunto da civilização que elabora esse produto intermediário entre o macho e o castrado que qualificam de feminino. (BEAUVOIR, 1967, p. 9). 
A análise de Beauvoir contribui para a desnaturalização do sexo, trazendo para o gênero aspectos sociológicos e culturais, evidenciando que o indivíduo não é predeterminado pelo critério biológico sexual com que nasceu.

O modo com que o indivíduo expressa o seu gênero é mais relevante, como seres humanos que convivem em sociedade, do que a sua formação genética.

Em linha de raciocínio mais específica com as demandas contemporâneas, escreve Judith Butler:

[...] os estilos têm uma história, e suas histórias condicionam e limitam suas possibilidades. Consideramos o gênero, por exemplo, como um estilo corporal, um 'ato', por assim dizer, que tanto é intencional como performativo, onde 'performativo' sugere uma construção dramática e contingente do sentido. (BUTLER, 2018, p. 240).

A transexualidade é, portanto, a expressão do sexo que é oposto ao sexo biológico do indivíduo. Dessa forma, o indivíduo que se identifica como mulher naturalmente assumirá um papel na sociedade visto, historicamente, como um papel feminino, ainda que sua genitália seja correlata ao sexo masculino. Nesse diapasão, Genival Veloso de França leciona que:

[...] Trata-se, pois, de uma inversão psicossocial, uma aversão e uma negação ao sexo de origem, o que leva esses indivíduos a protestarem e insistirem em uma forma de cura por meio da cirurgia de reversão genital, assumindo, assim, a identidade do seu desejado gênero. [...] As características clínicas da transexualidade se reforçam com a evidência da convicção de o indivíduo pertencer ao sexo oposto, o que lhe faz contestar e valer essa determinação até de forma violenta e desesperada. (FRANÇA, 2017, Epub).

Diante dos conceitos aqui expostos, é possível concluir que transexuais são pessoas que não se identificam com o sexo e atribuições físicas características do gênero que nasceram, o que leva à rejeição do próprio corpo e, muitas vezes, à realização de cirurgia de mudança de sexo.

\section{POSICIONAMENTOS DOUTRINÁRIOS}

Nesse diapasão, diante das evoluções sociais, surgem algumas indagações: dado que a transexual é vista como mulher pela sociedade e se identifica como mulher, seria esse um pressuposto para a incidência da qualificadora do feminicídio sendo a vítima uma pessoa transexual, desde que respeitados os princípios do Direito Penal?

Segundo a doutrina, existem duas correntes divergentes que se posicionam em relação à temática. Nesse seguimento, Rogério Sanches Cunha explica que:

[...] podem ser observadas duas posições: uma primeira, conservadora, entendendo que o transexual, geneticamente, não é mulher (apenas passa a ter órgão genital de conformidade feminina), e que, portanto, descarta, para a hipótese, a proteção especial; já para uma corrente mais moderna, desde que a pessoa portadora de transexualismo transmute suas características sexuais (por cirurgia e modo irreversível), deve ser encarada de acordo com sua nova realidade morfológica, eis que a jurisprudência admite, inclusive, retificação de registro civil. (CUNHA, 2018, p. 69).

Não obstante as denominações das correntes doutrinárias "moderna" e "conservadora" atribuam certo caráter de repulsa, ainda na primeira leitura, a doutrina majoritária adota ambas 
as nomenclaturas para as correntes. Dessa forma, estas serão também adotadas no presente trabalho.

\subsection{Corrente conservadora}

Para a corrente conservadora, mesmo que haja a cirurgia de mudança de sexo, a alteração no registro civil ou, ainda, que a aparência da vítima se assemelhe completamente à de uma pessoa identificada tipicamente como mulher pela sociedade, não existe a possibilidade de a pessoa transexual figurar como sujeito passivo na qualificadora do feminicídio. Nesse sentido, Cléber Masson defende o seu posicionamento:

Em primeiro lugar, admite-se a 'neocolpovulvoplastia', consistente na alteração do órgão sexual masculino para o feminino, com a construção de uma neovagina (vaginoplastia). Nessa hipótese, não há falar em feminicídio na morte do transexual, pois a vítima biologicamente não ostenta o sexo feminino, tanto que jamais poderá reproduzir-se, pela ausência dos órgãos internos. Essa situação é mantida ainda que a pessoa tenha sido beneficiada pela alteração do registro civil (mudança de nome). Com efeito, entendimento diverso seria prejudicial ao agente, constituindo-se em inquestionável analogia in malam partem, repudiada pelo moderno Direito Penal. (MASSON, 2021, p. 40).

No mesmo viés conceitual, Francisco Barros e Renee do Ó Souza defendem o critério biológico para a qualificadora do feminicídio:

Entendemos que deve ser sempre considerado o critério biológico, ou seja, identificase a mulher em sua concepção genética ou cromossômica. Neste caso, como a neocolpovulvoplastia altera a estética, mas não a concepção genética, não será possível a aplicação da qualificadora do feminicídio. (BARROS; SOUZA, 2019, Epub).

Observa-se que, para os defensores dessa linha de pensamento, o que determina o sexo feminino é a genética, a presença de órgãos sexuais internos e a capacidade de se reproduzir ao ostentar o sistema reprodutor feminino. Todavia, esse argumento apresenta lacunas na medida em que mulheres cisgêneros podem, por algum motivo de saúde, precisar realizar a cirurgia de retirada do órgão reprodutor e, assim, deixariam de ser acolhidas pela qualificadora, partindo do pressuposto que a definição de mulher advém da presença de órgãos reprodutores femininos. Do mesmo modo, existem mulheres que nascem estéreis, sendo incapazes de reproduzir mesmo possuindo todos os órgãos do sistema reprodutor feminino.

Para Masson (2021, p. 39), "o feminicídio constitui-se em circunstância pessoal ou subjetiva, pois diz respeito à motivação do agente". Portanto, para o autor, trata-se de uma qualificadora subjetiva, que se submete à vontade do agente, não se relacionando com os meios ou modos de execução.

Assim, utilizando-se do critério que define quem é mulher na qualificadora do feminicídio argumentado por Masson, torna-se inviável conciliar ambos os posicionamentos, uma vez que se trata de uma situação muito específica em que, para ser configurada a hipótese do feminicídio, o agente deveria ter conhecimento prévio da incapacidade da vítima de se reproduzir ou da ausência dos órgãos sexuais femininos dela.

Além disso, a qualificadora passaria a recair sob uma condição pré-existente na vítima e ignoraria completamente a motivação do agente, qual seja o menosprezo ou discriminação ao sexo feminino. 
Nota-se, ainda, que Masson (2021, p.40) afasta a hipótese de a pessoa que conquistou a alteração no seu registro civil também figurar como vítima na qualificadora, podendo a situação estar sujeita, segundo o autor, à analogia in malam partem, o que, no Direito Penal, não é permitido.

Acerca da analogia no Direito Penal, André Estefam leciona que:

[...] analogia constitui método de integração do ordenamento jurídico, em que se aplica uma regra existente para solucionar caso concreto semelhante, para o qual não tenha havido expressa regulamentação legal. [...] a proibição assinalada não se confunde com interpretação extensiva. Esta dá-se quando o agente extrai, da própria lei, seu verdadeiro alcance. Cuida-se de casos em que o legislador disse menos do que pretendia. [...]. (ESTEFAM, 2020, Epub).

Todavia, o debate no que diz respeito à possibilidade de a pessoa transexual figurar como vítima de feminicídio questiona o verdadeiro alcance da palavra mulher para o Direito Penal: quem é mulher e, portanto, quem poderá figurar no polo passivo da qualificadora do feminicídio?

Nesse diapasão, Brandão (2019, p. 49) leciona que "o bem jurídico tem uma função teleológica, isto é, uma função que visa esclarecer a finalidade da lei penal". Portanto, a fim de elucidar esse questionamento, é necessário não se atribuir da analogia, mas, sim, da interpretação extensiva, pois o intuito é entender qual o verdadeiro alcance da lei e o seu objetivo.

Nesse sentido, Rogério Greco explica o conceito de interpretação extensiva:

Ocorre a interpretação extensiva quando, para que se possa conhecer a exata amplitude da lei, o intérprete necessita alargar seu alcance, haja vista ter aquela dito menos do que efetivamente pretendia (lex minus dixit quam voluit). (GRECO, 2017, Epub).

Portanto, apenas partindo de uma interpretação extensiva do dispositivo legal é que será possível entender qual a sua amplitude e verdadeira finalidade.

\subsection{Corrente moderna}

Por outro lado, existe a corrente em que é defendida a possibilidade de a pessoa transexual figurar como vítima em crime de feminicídio.

Para Cunha, aquela que é reconhecida como mulher civilmente deverá também ser reconhecida como mulher no âmbito penal:

\footnotetext{
A nosso ver, a mulher de que trata a qualificadora é aquela assim reconhecida juridicamente. No caso de transexual que formalmente obtém o direito de ser identificado civilmente como mulher, não há como negar a incidência da lei penal porque, para todos os demais efeitos, esta pessoa será considerada mulher. (CUNHA, 2018, p. 70).
}

$\mathrm{Na}$ mesma linha de pensamento, Bitencourt afirma que existem três critérios para que se defina o sexo do indivíduo: o psicológico, o biológico e o jurídico. Na sua visão, o critério jurídico representa maior segurança jurídica na esfera penal, ou seja, para Bitencourt, será mulher para o Direito Penal aquela reconhecida também como mulher na esfera cível, contendo o sexo feminino em seus documentos de identificação. Assim leciona Cézar Bitencourt: 
Por isso, na nossa ótica, somente quem for oficialmente identificado como mulher (certidão do registro de nascimento, identidade civil ou passaporte), isto é, apresentar sua documentação civil identificando-a como mulher, poderá ser sujeito passivo dessa qualificadora. Nesse sentido, é irrelevante que tenha nascido do sexo feminino, ou que tenha adquirido posteriormente, por decisão judicial, a condição legalmente reconhecida como do sexo feminino. Nesses casos, não cabe discutir no juízo penal a justiça ou a injustiça, a correção ou a incorreção de sua natureza sexual. Cumpridas essas formalidades, a pessoa é reconhecida legalmente como do sexo feminino e ponto-final. É mulher e tem o direito de receber as mesmas garantias à mesma proteção legal dispensada a quem nasceu mulher. (BITENCOURT, 2018, Epub).

Os autores desta corrente baseiam as suas defesas no critério jurídico, sob o argumento de que traz ao Direito Penal maior segurança jurídica. Todavia, veja-se que o critério jurídico utilizado abrange a esfera cível, em que a transexual conquistou o seu direito de alteração do nome e sexo constantes no registro civil. Nesse sentido, Barros e Souza (2019, Epub) afirmam que "[...] o critério jurídico cível, data vênia, também não pode ser aplicado, pois as Instâncias cível e penal são independentes [...]".

Por outro lado, Greco ressalta a segurança jurídica que, para o autor, apenas o critério jurídico alcança:

\begin{abstract}
Com todo respeito às posições em contrário, entendemos que o único critério que nos traduz, com a segurança necessária exigida pelo Direito, e em especial o Direito Penal, é o critério que podemos denominar jurídico. Assim, somente aquele que for portador de um registro oficial (certidão de nascimento, documento de identidade) em que figure, expressamente, o seu sexo feminino, é que poderá ser considerado sujeito passivo do feminicídio. Aqui, pode ocorrer que a vítima tenha nascido com o sexo masculino, havendo tal fato constado expressamente de seu registro de nascimento. No entanto, posteriormente, ingressando com uma ação judicial, vê sua pretensão de mudança de sexo atendida, razão pela qual, por conta de uma determinação do Poder Judiciário, seu registro original vem a ser modificado, passando a constar, agora, como pessoa do sexo feminino. Somente a partir desse momento é que poderá, segundo nossa posição, ser considerada como sujeito passivo do feminicídio. (GRECO, 2017, Еpub).
\end{abstract}

Em vista disso, a discussão acerca do tema ganhou repercussão jurídica, inclusive nos tribunais superiores, originando um importante debate a respeito da incidência ou não da qualificadora do feminicídio quando a vítima é transexual.

\title{
4 REPERCUSSÃO NOS TRIBUNAIS
}

A priori, há de se ressaltar que, na esfera cível, o Supremo Tribunal Federal (STF) já consolidou entendimento acerca da mudança do nome e sexo no registro civil sem que haja, necessariamente, a cirurgia de mudança de sexo. Assim decidiu o STF:

AÇÃO DIRETA DE INCONSTITUCIONALIDADE. DIREITO CONSTITUCIONAL E REGISTRAL. PESSOA TRANSGÊNERO. ALTERAÇÃO DO PRENOME E DO SEXO NO REGISTRO CIVIL. POSSIBILIDADE. DIREITO AO NOME, AO RECONHECIMENTO DA PERSONALIDADE JURÍDICA, À LIBERDADE PESSOAL, À HONRA E À DIGNIDADE. INEXIGIBILIDADE DE CIRURGIA DE TRANSGENITALIZAÇÃO OU DA REALIZAÇÃO DE TRATAMENTOS HORMONAIS OU PATOLOGIZANTES. 1. O direito à igualdade sem discriminações abrange a identidade ou expressão de gênero. 2. A identidade de gênero é manifestação da própria personalidade da pessoa humana e, como tal, cabe ao Estado apenas o papel de reconhecê-la, nunca de constituí-la. 3. A pessoa 
transgênero que comprove sua identidade de gênero dissonante daquela que lhe foi designada ao nascer por autoidentificação firmada em declaração escrita desta sua vontade dispõe do direito fundamental subjetivo à alteração do prenome e da classificação de gênero no registro civil pela via administrativa ou judicial, independentemente de procedimento cirúrgico e laudos de terceiros, por se tratar de tema relativo ao direito fundamental ao livre desenvolvimento da personalidade. 4. Ação direta julgada procedente. (ADI 4.275, DF - Relator Ministro Marco Aurélio, DJe 01/03/2018)

Portanto, observa-se que na esfera cível existem aparatos jurídico-legais que permitem à pessoa transexual ser reconhecida de acordo com a sua identidade de gênero, não se sujeitando ao sexo biológico constante no seu registro civil.

Em face do exposto, ficou demonstrado que, conforme defendido por uma parte da doutrina, é possível aplicar a qualificadora do feminicídio aos casos em que a vítima for uma mulher transexual, ainda que a lei não seja clara em relação à hipótese.

Partindo desse pressuposto, diversos tribunais vêm aplicando o entendimento da corrente moderna no tocante à possibilidade da incidência da qualificadora do feminicídio. Serão demonstrados dois casos: um que se trata do art. $121, \S 2^{\circ}$-A, II (menosprezo ou discriminação à condição de mulher), e outro do art. 121, §2-A, I (violência doméstica ou familiar), ambos do Código Penal.

\subsection{Incidência da qualificadora do feminicídio em caso de menosprezo ou discriminação à condição de mulher}

No processo de $\mathrm{n}^{\mathrm{o}}$ 0001842-95.2018.8.07.0007, do Tribunal de Justiça do Distrito Federal e Territórios (TJDFT), o relator Desembargador Waldir Leôncio Lopes Júnior fundamentou sua decisão de indeferimento do recurso em sentido estrito, em face da decisão de pronúncia, interposto pelos réus da ação da seguinte forma:

\footnotetext{
No caso, há elementos indicativos de que o homicídio tentado teria sido praticado por repúdio ao gênero da ofendida. Colhe-se dos autos que a vítima JÉSSICA OLIVEIRA DA SILVA, apesar de ostentar o sexo biológico masculino, adota a identidade de gênero feminina, com a correspondente alteração do registro civil (fl. 87), sendo, portanto, uma mulher transgênero. A abrangência da conceituação histórico-social do gênero é superior a do sexo biológico, pois trata de características psicológicas e comportamentais do indivíduo, a depender de seu fenótipo, se masculino ou feminino. [...] Este Relator não desconhece a polêmica que envolve a questão. Também é sabido que há posição doutrinária no sentido de admitir a figura do feminicídio apenas contra vítimas do sexo biológico e registral feminino, bem como que, para parte da corrente doutrinária menos conservadora, somente as transexuais femininas submetidas à cirurgia de redesignação sexual e com alteração no registro civil poderiam ser vítimas da mencionada forma qualificada do homicídio. Por outro lado, não se pode deixar de considerar a situação de dupla vulnerabilidade a que as pessoas transgêneros femininas, grupo ao qual pertence a ofendida, são expostas "por um lado, em virtude da discriminação existente em relação ao gênero feminino, e de outro, pelo preconceito de parte da sociedade ao buscarem o reconhecimento de sua identidade de gênero".
}

Observe-se que o Desembargador ressalta a importância do conceito social de gênero, sendo este mais relevante para identificar as motivações do agente no crime de feminicídio, visto que se trata de uma qualificadora objetiva quanto ao sujeito passivo, todavia subjetiva quanto ao animus necandi. 
O Douto Juízo ainda explica que, conforme as provas apuradas nos autos do processo, os acusados repetiam, durantes as agressões, que era para a vítima "virar homem". Desse modo, para o relator, ficou evidente o animus necandi em virtude de a vítima ser uma mulher transexual. Assim prosseguiu o relator:

\begin{abstract}
Para os Tribunais pátrios, a amplitude que se deve dar ao sujeito passivo do tipo penal do feminicídio é tema ainda mais recente, revelando o ineditismo da matéria. $\mathrm{Na}$ espécie, a inclusão da qualificadora do feminicídio decorreu do fato de o crime ter sido praticado (fl. 2B), "por ódio à condição de transexual de Jéssica", uma vez que, enquanto os acusados agrediam fisicamente a vítima, também diziam a ela que "era para virar homem". Assim, malgrado os fatos descritos na denúncia não se tratarem de violência praticada no âmbito doméstico e familiar, a imputação do feminicídio se deveu ao menosprezo ou discriminação à condição de mulher trans da ofendida (inciso II do $\S 2^{\circ}$-A do art. 121 do CP), extraídos da conduta delitiva preconceituosa atribuída aos réus. Diante disso, os indícios da presença da qualificadora estão, em tese, fundamentados no acervo probatório.
\end{abstract}

Posteriormente, a incidência da qualificadora do feminicídio foi novamente questionada pela defesa dos réus ao ser impetrado habeas corpus, não conhecido pelo Superior Tribunal de Justiça (STJ). O relator Ministro Joel Ilan Paciornik proferiu o seu voto citando a decisão do tribunal de origem e defendendo a manutenção da qualificadora do feminicídio nos seguintes termos:

[...] Enfim, a Constituição deve ser levada a sério, numa hermenêutica responsável, cumprindo ao juiz, ao verificar a violação de direitos, fazê-los respeitar. Somente através dessa prerrogativa constitucional irrenunciável é que se evita a banalidade do mal, muito bem abordada por Alberto Alonso Muños (Eichmann em Jerusalém e a banalidade do mal na decisão do juiz. Boletim do IBCCRIM. Ano14, n.52, jan-mar. 2011, p.15).

Destarte, para o TJDFT e para o STJ, a vítima no caso em apreço sofreu a tentativa de homicídio em virtude da sua condição de ser mulher, levando em consideração o nome social feminino adotado, comportamentos ditos culturalmente femininos e, com isso, vista pela sociedade como uma mulher, ficando sujeita às violências de gênero e, portanto, sendo necessária a tutela do Estado em virtude da sua vulnerabilidade na condição de mulher.

\title{
4.2 Incidência da qualificadora do feminicídio em caso de violência doméstica ou familiar
}

A violência de gênero praticada contra mulheres apresenta maior índice quando é acometida no âmbito da violência doméstica. Segundo o Fórum Brasileiro de Segurança Pública, das 1.326 vítimas de feminicídio registradas em 2019 no Brasil, 89,9\% delas foram mortas pelo companheiro ou ex-companheiro.

À vista disso é que a Lei Maria da Penha (Lei 11.340/2006) busca garantir à mulher que sofre ameaças, agressões ou até perigo de um mal maior, segurança por meio de medidas protetivas.

Entretanto, quando o agressor torna a aumentar as agressões e termina por ceifar a vida de sua companheira ou ex-companheira, classificar-se-á o crime como homicídio qualificado pelo feminicídio.

Destarte, objetivando atingir a finalidade da referida qualificadora e garantir os direitos das transexuais, a jurisprudência vem admitindo a incidência da qualificadora do feminicídio em caso de violência doméstica ou familiar sendo a vítima uma mulher transexual. Assim 
decidiu a Juíza de Direito Dra. Patrícia Inigo Funes e Silva pela pronúncia do réu acusado de feminicídio contra a sua companheira:

[...] Com efeito, diante do conceito social de mulher, incluindo-se neste as transexuais, nos termos acima explicitados, verifico que a qualificadora do feminicídio, narrada na denúncia não pode ser afastada, pois coerente com a prova oral produzida. Referida prova indica a existência de indícios de que o réu teria cometido o delito contra mulher, por razão da condição de sexo feminino, no contexto de violência doméstica e familiar, eis que teria empregado violência contra a vítima Michele, com quem convivia e tinha relação íntima de afeto.

Da mesma forma como foi defendido pelo Desembargador Waldir Leôncio Lopes Júnior na decisão exposta no capítulo anterior, a Juíza no caso em foco ressalta o conceito social de mulher para admitir quem será tutelada pela Lei do Feminicídio.

No caso em apreço, leva-se em consideração o comportamento da vítima visto historicamente como feminino pela sociedade, acrescentado da agressão advinda do seu companheiro, caracterizando a violência doméstica. Portanto, é imprescindível a aplicação da qualificadora do feminicídio no determinado caso.

\section{CONCLUSÃO}

Por conseguinte, ficou demonstrado que, por meio da análise profunda e da atribuição do conceito social ao termo mulher, é possível incidir a qualificadora do feminicídio (art. 121, $\S 2^{\circ}$, VI do Código Penal) em casos cuja vítima seja uma mulher transexual.

Isso porque, a transexual que se assume como mulher no meio social será enxergada na sociedade como tal, arcando, inclusive, com preconceitos não apenas em virtude da sua transexualidade mas também pelo fato de ser uma mulher. Ela será vista pelo feminicida como uma pessoa inferior, inclusive em relacionamentos e no âmbito familiar, necessitando da proteção de leis que visam combater a violência de gênero, entre elas, a qualificadora do feminicídio.

Note que, por um lado, existe o argumento de que a norma deve ser interpretada o mais restritivamente possível, já que se trata de uma norma penal, sob o risco de acometer a analogia in malam partem. Por outro lado, a norma precisa acompanhar a evolução social e preservar os princípios constitucionais, tal qual o princípio da dignidade da pessoa humana, previsto no art. $1^{\circ}$, inciso III, da Constituição Federal.

Desse modo, uma vez que a transexual é vista socialmente como mulher e assim se identifica, o seu impacto na sociedade como um todo é muito mais relevante do que se restringir ao critério biológico, como defendido pela corrente conservadora.

Perante isso, excluir as mulheres transexuais da tutela do feminicídio é não atender à total finalidade da lei, conforme analisado por meio da interpretação extensiva do dispositivo legal, uma vez que essas mulheres estão sujeitas à violência em razão do gênero e à violência doméstica tanto quanto as mulheres cisgêneros.

Percebe-se que, nas jurisprudências analisadas no presente trabalho, ambas as vítimas possuíam alteração do nome no registro civil, portanto, em consonância com a parte da corrente moderna que adota o critério jurídico.

Todavia, para que haja maior segurança jurídica e proteção devida a todas as mulheres, é necessária uma adaptação na Lei do Feminicídio, a exemplo do Projeto de Lei do Senado $\mathrm{n}^{\text {o }}$ 191, que propõe alteração na Lei Maria da Penha para que a referida norma assegure proteção a todas as mulheres, independentemente da sua identidade de gênero. 
Tal alteração, se aprovada, representará enorme evolução na Lei Maria da Penha, que visa proteger mulheres em situação de vulnerabilidade no âmbito de violência doméstica. E para isso, em conformidade com a Constituição Federal de 1988, garantidora de diversos direitos fundamentais, é necessário que não haja a exclusão de nenhuma mulher da tutela desses direitos, estando inclusas as mulheres transexuais.

Desse modo, a exemplo do citado Projeto de Lei, visando atingir os princípios do Estado Democrático de Direito e alcançar a efetiva proteção pretendida pela Lei do Feminicídio a todas as mulheres, preservando o princípio da legalidade, é imprescindível que a norma penal sofra alteração legislativa a fim de conter em seu texto legal a extensão da tutela do Estado na qualificadora do feminicídio a todas as mulheres.

\section{REFERÊNCIAS}

BARROS, Francisco Dirceu; SOUZA, Renee do Ó. Feminicídio: controvérsias e aspectos práticos. São Paulo: JH Mizuno, 2019. Epub.

BEAUVOIR. Simone de. O Segundo Sexo: a experiência vivida. V. 2. Tradução de Sérgio Milliet. 2. ed. São Paulo: Difusão Europeia do Livro, 1967. Disponível em: https://www.afoiceeomartelo.com.br/posfsa/Autores/Beauvoir,\%20Simone\%20de/O\%20Segu ndo\%20Sexo\%20-\%20II.pdf

BITENCOURT, Cezar Roberto. Tratado de direito penal: parte especial. Vol. 2. 18 ed. São Paulo: Saraiva Educação, 2018. Epub.

BRANDÃO, Cláudio. Teoria Jurídica do Crime. Coleção: Ciência Criminal Contemporânea. Vol. 1. 5 ${ }^{\text {a }}$ ed. Belo Horizonte: Editora D’Plácido, 2019.

BRASIL. Conselho Federal de Medicina. Resolução no 2.265, de 20 de setembro de 2019. Dispõe sobre o cuidado específico à pessoa com incongruência de gênero ou transgênero e revoga a Resolução CFM no 1.955/2010. Disponível em: https://www.in.gov.br/en/web/dou//resolucao-n-2.265-de-20-de-setembro-de-2019-237203294. Acesso em: 20 maio 2021.

BRASIL. Constituição (1988): Constituição da República Federativa do Brasil de 1988. Brasília, DF: Presidência da República. Disponível em: http://www.planalto.gov.br/ccivil_03/constituicao/constituicao.htm. Acesso em: 18 maio 2021.

BRASIL. Código Penal (1940): Decreto-Lei no 2.848 de 1940. Rio de Janeiro, RJ: Presidência da República. Disponível em: http://www.planalto.gov.br/ccivil_03/decretolei/del2848compilado.htm. Acesso em: 18 maio 2021.

BRASIL. Lei $\quad \mathbf{n}^{0} \quad \mathbf{8 . 0 7 2}$ de 1990: Dispõe sobre os crimes hediondos, nos termos do art. $5^{\circ}$, inciso XLIII, da Constituição Federal, e determina outras providências. Brasília, DF: Presidência da República. Disponível em: http://www.planalto.gov.br/ccivil_03/leis/L8072compilada.htm. Acesso em: 18 maio 2021.

BRASIL. Lei $\mathbf{n}^{0}$ 11.340, de 7 de agosto de 2006: Cria mecanismos para coibir a violência doméstica e familiar contra a mulher, nos termos do $\S 8^{\circ}$ do art. 226 da Constituição Federal, da Convenção sobre a Eliminação de Todas as Formas de Discriminação contra as Mulheres e 
da Convenção Interamericana para Prevenir, Punir e Erradicar a Violência contra a Mulher; dispõe sobre a criação dos Juizados de Violência Doméstica e Familiar contra a Mulher; altera o Código de Processo Penal, o Código Penal e a Lei de Execução Penal; e dá outras providências. Brasília, DF: Presidência da República. Disponível em: http://www.planalto.gov.br/ccivil_03/_ato2004-2006/2006/lei/111340.htm. Acesso em: 18 maio 2021.

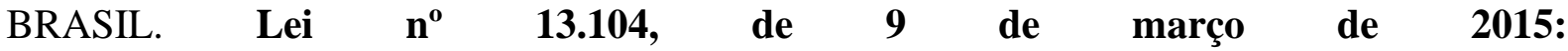
Altera o art. 121 do Decreto-Lei n ${ }^{\circ} 2.848$, de 7 de dezembro de 1940 - Código Penal, para prever o feminicídio como circunstância qualificadora do crime de homicídio, e o art. $1^{\circ}$ da Lei ${ }^{\circ}$ 8.072, de 25 de julho de 1990, para incluir o feminicídio no rol dos crimes hediondos. Brasília, DF: Presidência da República. Disponível em: http://www.planalto.gov.br/ccivil_03/_ato20152018/2015/lei/113104.htm. Acesso em: 18 maio 2021.

BRASIL. Superior Tribunal de Justiça. Habeas Corpus $n^{\circ}$ 541.237/DF. Habeas corpus substitutivo de recurso próprio. Direito penal. Tribunal do júri. Feminicídio tentado. Vítima transexual. Pedido de exclusão da qualificadora. Tese a ser apreciada pelo conselho de sentença. Princípio in dubio pro societate. Exclusão da qualificadora. Improcedente. Habeas corpus não conhecido. Relator: Min. Joel Ilan Paciornik, 15 dez. 2020. Diário de Justiça Eletrônico, Brasília, DF, 18 dez. 2020. Disponível em: https://processo.stj.jus.br/processo/julgamento/eletronico/documento/mediado/?documento_ti po $=5 \&$ documento_sequencial $=1$ 19581952\&registro_numero $=201903166711 \&$ peticao_numer o=-1\&publicacao_data=20201218\&formato=PDF. Acesso em: 18 mai. 2021.

BRASIL. Supremo Tribunal Federal. Ação Direta de Inconstitucionalidade 4.275/DF. Ação direta de inconstitucionalidade. Direito constitucional e registral. Pessoa transgênero. Alteração do prenome e do sexo no registro civil. Possibilidade. Direito ao nome, ao reconhecimento da personalidade jurídica, à liberdade pessoal, à honra e à dignidade. Inexigibilidade de cirurgia de transgenitalização ou da realização de tratamentos hormonais ou patologizantes. Relator: Min. Marco Aurélio, 01 mar. 2018. Brasília: STF, [2018]. Disponível em: https://redir.stf.jus.br/paginadorpub/paginador.jsp?docTP=TP\&docID=749297200. Acesso em: 18 maio 2021.

BUTLER, Judith. Problemas de gênero: feminismo e subversão da identidade. $16^{\mathrm{a}}$ ed. Rio de Janeiro: Civilização Brasileira, 2018.

CAPEZ, Fernando. Curso de direito penal: parte especial. Vol. 2. 19a ed. São Paulo: Saraiva Educação, 2019. Epub. Acesso em: 20 maio 2021.

CUNHA, Rogério Sanches. Manual de direito penal: parte especial. $10^{\mathrm{a}}$ ed. Salvador: JusPODIVM, 2018.

DISTRITO FEDERAL. Tribunal de Justiça. Acórdão n 1184804. Direito penal e processual penal. Recurso em sentido estrito. Pronúncia. Feminicídio tentado. Vítima mulher transgênero. Menosprezo ou discriminação à condição de mulher. Materialidade e indícios de autoria presentes. Pedido de desclassificação. Improcedente. Teses a serem apreciadas pelos jurados. Princípio in dubio pro societate. Exclusão da qualificadora. Improcedente. Recursos conhecidos e desprovidos. Relator: Desembargador Waldir Leôncio Lopes Júnior, 4 jul. 2019. Brasília, DF. Disponível em: https://pesquisajuris.tjdft.jus.br/IndexadorAcordaos- 
web/sistj?visaoId=tjdf.sistj. acordaoeletronico.buscaindexada. apresentacao.VisaoBuscaAcorda o\&controladorId=tjdf.sistj. acordaoeletronico.buscaindexada. apresentacao.ControladorBuscaA cordao\&visaoAnterior $=\mathrm{tj}$ df.sistj.acordaoeletronico.buscaindexada.apresentacao.VisaoBuscaA cordao\&nomeDaPagina $=$ resultado $\&$ comando $=$ abrirDadosDoAcordao\&enderecoDoServlet $=\mathrm{si}$ stj\&historicoDePaginas $=$ buscaLivre \&quantidadeDeRegistros $=20 \&$ baseSelecionada $=$ BASE ACORDAOS \&numeroDaUltimaPagina $=1 \&$ buscaIndexada $=1 \&$ mostrarPaginaSelecaoTipoRe sultado $=$ false $\&$ totalHits $=1 \&$ internet $=1 \&$ numeroDoDocumento $=1184804$. Acesso em: 18 mai. 2021.

ESTEFAM, André. Direito Penal: Parte Geral. Vol. 1. 9a ed. São Paulo: Saraiva Educação, 2020. Epub.

FRANÇA, Genival Veloso de. Medicina Legal. $11^{\mathrm{a}}$ ed. Rio de Janeiro: Guanabara Koogan, 2017. Epub.

FÓRUM BRASILEIRO DE SEGURANÇA PÚBLICA. Anuário Brasileiro de Segurança Pública 2020. 2020. Disponível em: https://forumseguranca.org.br/wpcontent/uploads/2021/02/anuario-2020-final-100221.pdf. Acesso em: 20 maio 2021.

GALVÃO, Juliana de Castro. Desigualdade salarial entre homens e mulheres. Politize!, 02 mar. 2016. Disponível em: https://www.politize.com.br/desigualdade-salarial-entre-homens-emulheres/. Acesso em: 25 maio 2021.

GRECO, Rogério. Curso de Direito Penal: parte especial. Vol. 2. 14 a ed. Rio de Janeiro: Impetus, 2017. Epub.

GRECO, Rogério. Curso de Direito Penal: parte geral. Vol. 1. 19ª ed. Rio de Janeiro: Impetus, 2017. Epub.

GÊNERO. In: DICIO, Dicionário Online de Português. Disponível em: https://www.dicio.com.br/genero/. Acesso em: 20 maio 2021.

JUNIOR, Eudes Quintino de Oliveira. O transexual e o crime de feminicídio. Migalhas, 13 nov. 2016. Disponível em: https://www.migalhas.com.br/depeso/248860/o-transexual-e-ocrime-de-feminicidio. Acesso em: 25 maio 2021.

JUNIOR, Eudes Quintino de Oliveira; SECANHO, Antonelli Antonio Moreira. A analogia e a interpretação extensiva no Direito Penal. Migalhas, 12 ago. 2013. Disponível em: https://www.migalhas.com.br/depeso/184197/a-analogia-e-a-interpretacao-extensiva-nodireito-penal. Acesso em: 25 maio 2021.

LIMA, Daniel; NETO, José Muniz. Analogia e Interpretação em Direito Penal: o que precisamos saber?. Canal Ciências Criminais, 01 maio 2020. Disponível em: https://canalcienciascriminais.com.br/analogia-e-interpretacao-em-direito-penal-o-queprecisamos-

saber/\#: :text=Sobre\%20interpreta\%C3\%A7\%C3\%A3o\%20extensiva\%20temos\%20o,se\%20 entende\%20por\%20\%E2\%80\%9Ccasa\%E2\%80\%9D. Acesso em: 25 maio 2021. 
MARQUES, Teresa Cristina de Novaes. O voto feminino no Brasil. $2^{\mathrm{a}}$ ed. Brasília: Câmara do Deputados, Edições Câmara, 2019.

MASSON, Cleber. Direito Penal: parte especial. Vol. 2. 14 a ed. Rio de Janeiro: Forense; São Paulo: MÉTODO, 2021.

MIGUENS, Marcela Siqueira; RIBEIRO, Raisa Duarte da Silva. González e outras ("campo algodoeiro") vs. México (2009): violência contra a mulher e definição de feminicídio. Núcleo Interamericano de Direitos Humanos da Faculdade Nacional de Direito da UFRJ (NIDH), 22 fev. 2018. Disponível em: https://nidh.com.br/gonzalez-e-outras-campo-algodoeiro-vsmexico-2009-violencia-contra-a-mulher-e-definicao-de-feminicidio/. Acesso em: 25 maio 2021.

MP OFERECE primeira denúncia por feminicídio de transexual em SP. Portal G1, São Paulo, 06 out. 2016. Disponível em: http://g1.globo.com/sao-paulo/noticia/2016/10/mp-ofereceprimeira-denuncia-por-feminicidio-de-transexual-em-sp.html. Acesso em: 25 maio 2021.

PIMENTEL, Sílvia. Gênero e direito. Enciclopédia jurídica da PUC-SP. Celso Fernandes Campilongo, Alvaro de Azevedo Gonzaga e André Luiz Freire (coords.). Tomo: Teoria Geral e Filosofia do Direito. Celso Fernandes Campilongo, Alvaro de Azevedo Gonzaga, André Luiz Freire (coord. de tomo). 1. ed. São Paulo: Pontifícia Universidade Católica de São Paulo, 2017. Disponível em: https://enciclopediajuridica.pucsp.br/verbete/122/edicao-1/genero-e-direito. Acesso em: 25 maio 2021.

SANTOS, Deise da Rocha Dias; SANTOS, William Oliveira dos. Aspectos relacionados ao feminicídio dentro do ordenamento jurídico brasileiro. Âmbito Jurídico, 01 dez. 2017. Disponível em: https://ambitojuridico.com.br/cadernos/direito-penal/aspectos-relacionadosao-feminicidio-dentro-do-ordenamento-juridico-brasileiro/. Acesso em: 25 maio 2021.

SÃO PAULO. Tribunal de Justiça ( $3^{a}$ Vara do Júri - Comarca de São Paulo). Sentença de Pronúncia. Processo no : 0001798-78.2016.9.26.0052. Juíza de Direito: Dra. Patrícia Inigo Funes e Silva, 28 fev. 2018. São Paulo, SP. Disponível em: https://esaj.tjsp.jus.br/pastadigital/abrirDocumentoEdt.do?nuProcesso=0001798-

78.2016.8.26.0052\&cdProcesso $=1$ G0001U990000 $\&$ cdForo $=52 \&$ baseIndice $=$ INDDS\&nmAli as $=$ PG5BF $\&$ tpOrigem $=2 \&$ flOrigem $=P \&$ cdServico $=190101 \&$ acessibilidade $=$ false $\&$ ticket $=\mathrm{gv}$ O66HudPBNodbK8ERQwgso7DbaRQP0ciU9v3jTQY9DeBxdKdyk\%2FYfy\%2FDhiHd\%2B mJ073z0TnKJxYh8\%2BesNve6\%2B\%2BOiCmnwD082Bhwt7VI69S2iUEcHmbHPc5dZDX QxN9dhSSa\%2FaaSwdKVZgUo3VY5mVJXav8I0xIIxnkJKU8XBAhT1vZtkMsMoTCfZC2 FQSIsd0raz0XiJ8ObWrkC7Di\%2Bz4EL81nfhQe\%2FCT7MZM4YD4xJAiwSG8E4VI2hXB pD4DGoZBRcr3B2VjNyFT8loyDcfiVzfeXyiKKtZpGxBKXxfzJHPblZsfOG\%2BHcFKmZu eqqVJLszVVNIB\%2F4DWuyUqVOqzRngLpCVfk3sXxcpzOb2ok\%2BD395n0QYXjMVQK EG123wZg. Acesso em: 18 mai. 2021.

SEXO. In: DICIO, Dicionário Online de Português. Disponível em: https://www.dicio.com.br/sexo/. Acesso em: 20 maio 2021.

SIEGFRIED, Kristy. Violência contra a mulher aumenta durante a pandemia de COVID-19: Dados mostram que mulheres e meninas deslocadas em todo o mundo estão enfrentando aumento da violência de gênero durante a pandemia de COVID-19. Alto Comissariado das 
Nações Unidas para Refugiados (ACNUR), 25 nov. 2020. Disponível em: https://www.acnur.org/portugues/2020/11/25/violencia-contra-a-mulher-aumenta-durante-apandemia-de-covid-19/. Acesso em: 25 maio 2021.

SOUSA, Jéssica Moreira de. A Possibilidade Jurídica de a transexual figurar como sujeito passivo no crime de feminicídio. Âmbito Jurídico, 01 fev. 2021. Disponível em: https://ambitojuridico.com.br/cadernos/direito-penal/a-possibilidade-juridica-de-a-transexualfigurar-como-sujeito-passivo-no-crime-de-feminicidio/. Acesso em: 25 maio 2021.

VIANA, Jorge. Projeto de Lei n. 191, de 2017. Altera a redação do art. $2^{\circ}$ da Lei no 11.340 , de 7 de agosto de 2006 - Lei Maria da Penha -, para assegurar à mulher as oportunidades e facilidades para viver sem violência, independentemente de sua identidade de gênero. Brasília: Senado Federal, 2017. Disponível em: https://legis.senado.leg.br/sdleggetter/documento?dm=5339539\&ts=1593911503843\&disposition=inline. Acesso em: 18 mai. 2021. 